\title{
BALANCED SCORECARD: UTILIZAÇÃO DA PERSPECTIVA DO CLIENTE NA AVALIAÇÃO DO SUPERMERCADO X
}

\author{
BALANCED SCORECARD: USING THE CUSTOMER'S PERSPECTIVE IN SUPERMARKET \\ ASSESSMENT X
}

\section{Maira Sgarbossa}

Universidade de Passo Fundo - UPF, RS, Brasil, maira.sgarbossa@hotmail.com

Mirna Muraro

Universidade de Passo Fundo - UPF, RS, Brasil, mirna@upf.br

\begin{abstract}
Resumo: Diante do cenário econômico em constante desenvolvimento decorrente do processo da globalização e concorrência, as empresas necessitam de uma gestão que possibilite o atendimento de seus objetivos e metas. A controladoria através do uso do Balanced Scorecard (BSC) permite uma visão balanceada e integrada dos processos, garantindo que os esforços da organização se direcionem para a criação de valor. Assim, o objetivo desse estudo consiste em avaliar o desempenho financeiro e organizacional do supermercado $\mathrm{X}$ através da perspectiva do cliente, uma dentre as quatro abordadas pelo BSC. Metodologicamente, trata-se de um estudo aplicado de caráter descritivo, com abordagem quantitativa, realizado através de um levantamento junto aos clientes do estabelecimento. Ao final, percebe-se a gestáo organizacional do supermercado que visa ampliaçóes, criaçáo de novos departamentos e principalmente qualidade dos produtos vendidos, refletiu na sua lucratividade e na fidelização de clientes. Identificou-se que 53\% dos clientes entrevistados realizam suas compras a mais de dez anos no Supermercado X; $44 \%$ destes clientes reconhecem a qualidade dos produtos do supermercado e os adquirem mesmo que o preço seja superior aos outros estabelecimentos da cidade; e $50 \%$ dos clientes destacam a padaria como o melhor departamento do mercado, pela qualidade dos produtos produzidos e comercializados.
\end{abstract}

Palavras-chave: Controladoria. Balanced Scorecard. Cliente.

\begin{abstract}
In view of the constantly evolving economic scenario resulting from the globalization and competition process, companies need management that allows them to meet their objectives and goals. Controllership using the Balanced Scorecard (BSC) allows a balanced and integrated view of processes, ensuring that the organization's efforts are directed towards creating value. Thus, the objective of this study is to evaluate the financial and organizational performance of supermarket $\mathrm{X}$ through the customer's perspective, one of the four approached by the BSC. Methodologically, it is an applied study of a descriptive character, with a quantitative approach, carried out through a survey with the establishment's customers. In the end, we can see the organizational management of the supermarket, which aims to expand, create new departments and mainly the quality of products sold, reflected in its profitability and customer loyalty. It was identified that $53 \%$ of the interviewed customers made their purchases for more than ten years at supermarket X; $44 \%$ of these customers recognize the quality of the supermarket's products and purchase them even if the price is higher than other establishments in the city; and $50 \%$ of customers highlight the bakery as the best department in the market, due to the quality of the products produced and marketed.
\end{abstract}

Keywords: Controllership. Balanced Scorecard. Client. 


\section{INTRODUÇÃO}

Diante das inúmeras mudanças ocorridas na sociedade decorrentes do efeito globalização, as empresas passaram a necessitar de uma organização interna cada vez mais sofisticada, fazendo com que sua finalidade seja a garantia de informaçóes adequadas ao processo decisório, auxiliando os administradores e gestores na busca da eficácia gerencial. (CUNHA; SANTOS, 2013).

A necessidade de criação de valor sempre esteve presente no ambiente dos negócios. O sucesso de um empreendimento está na sua intenção principal, naquilo que está definido na sua missão e visão, na sua definição estratégica. (KRAEMER, 2002; 2005).

A sociedade do conhecimento mencionada por Herrero Filho (2005) alude que medir apenas a saúde financeira de uma empresa não é mais suficiente, é preciso medir também a saúde estratégica no longo prazo. Diante desse cenário, marcado por alta competitividade e acirrada concorrência a utilização do Balanced Scorecard (BSC), criado por Kaplan e Norton (1997), facilita o processo de planejamento e controle nas empresas, especificamente no ajuste entre os objetivos estratégicos e os planos operacionais, identificando as razóes de seu fracasso e/ou sucesso (ROCHA; LAVARDA, 2009).

Tal ferramenta centra sua atenção nas perspectivas: financeiras, do cliente, dos processos internos e do aprendizado e crescimento, vértices essas, que impulsionam as empresas a analisarem fatores intangíveis e estratégicos de grande relevância para o sucesso do negócio. (HERRERO FILHO, 2005).

Frente à necessidade de conhecer e colocar em prática a estratégia da empresa em busca do desempenho ideal junto a população consumidora, este trabalho tem por objetivo identificar através da perspectiva do cliente, uma dentre as quatro abordadas pelo BSC, como os clientes do supermercado X avaliam sua performance organizacional, quanto ao atendimento, produtos/serviços prestados, preços e demais fatores que influenciam nas decisóes de compra pelo consumidor, a fim de avaliar o desempenho financeiro e organizacional do supermercado $\mathrm{X}$, buscando elevar e atender as expectativas e reconhecimento dos mesmos (clientes), e em consequência propagar a rentabilidade do negócio.

Dessa forma, o problema de pesquisa que este artigo busca responder é: o desempenho financeiro e organizacional do supermercado X pode ser avaliado através da perspectiva de seus clientes?

Destacam-se como objetivos específicos, que vão ao encontro da solução do problema: determinar indicadores de perspectiva de clientes para o supermercado X, aplicar um questionário junto aos clientes do Supermercado X, avaliando suas perspectivas e se as mesmas estáo sendo atendidas e identificar se existe influência dos preços cobrados na escolha de compra no supermercado.

A justificativa deste trabalho se dá em razão da necessidade dos estabelecimentos comerciais, em especial o Supermercado X, em conhecer as preferências, afinidade, avaliação e reconhecimento percebidos por seus consumidores, para o aumento do valor percebido em relação aos seus produtos, marcas, serviços, experiência de compra e relacionamento.

Assim, o conhecimento desse conjunto de fatores intangíveis é importante, uma vez que somente existirá agregaçáo de valor se o período de relacionamento com o cliente se manter ao longo do seu ciclo operacional, principalmente em um ramo táo competitivo, no qual a confiabilidade do cliente para com a empresa é percebida pela qualidade dos serviços e produtos oferecidos. 


\section{REFERÊNCIAL TEÓRICO}

Neste item são apresentados os conceitos principais sobre contabilidade gerencial, controladoria e Balanced Scorecard.

\subsection{Contabilidade Gerencial}

Com a grande competitividade existente entre as organizaçóes, a elaboração e a implantação de estratégias visando a vantagem competitiva e o valor agregado aos produtos e serviços, tornou-se comum no alcance das metas e objetivos da organização. (NASCIMENTO; CAVENAGHI, 2008).

Para Schmidt (2000) foi nesse mesmo momento, marcado por intensas mudanças que uma das primeiras contribuiçóes da contabilidade gerencial foi realizada: apresentação de formas para calcular o custo de produçáo real, que em conjunto com a contabilidade como um todo, era utilizada como fonte de informaçóes e para controle dos resultados da gestáo.

Para Grzeszezeszyn (2005) a contabilidade gerencial pode receber diversas definiçóes, mas as palavras-chaves para seu entendimento são informação e gestão. A contabilidade gerencial é aquela que produz informaçóes operacionais e financeiras para funcionários e administradores.

Como parte do sistema contábil, a contabilidade gerencial dedica-se quanto às informaçôes para os usuários internos, sendo abrangente e concisa, ajustando-se constantemente para adequar-se às mudanças tecnológicas e ás necessidades dos gestores em novas abordagens e em outras áreas funcionais dos negócios. (FREZATTI; GUERREIRO; AGUIAR, 2007).

O objetivo da contabilidade gerencial citado por Menezes (2010) é de fazer a conexão entre as açôes locais dos gerentes e a lucratividade da empresa, para que eles possam saber quais das suas açóes levam a empresa em direção à sua meta. Compondo o processo de gestão, a contabilidade gerencial mencionada por Padoveze (1999, p. 3) "adiciona valor distintivamente pela investigaçáo continua sobre a efetividade da utilização dos recursos pelas organizaçóes, na criação de valor para acionistas, clientes e outros credores".

Menezes (2010) apresenta como principal função da contabilidade gerencial, servir como importante ferramenta no processo de tomada de decisão, garantindo que as informaçóes cheguem às pessoas certas no tempo certo, para um controle eficaz das atividades da empresa, a fim de permitir à administraçáo o conhecimento dos fatos ocorridos e seus resultados.

Para tal, as empresas passaram a utilizar artifícios da controladoria para suprir as lacunas do sistema de contabilidade financeira e fiscal, este desprovido de informaçôes tempestivas para o processo de gestão.

\subsection{Controladoria}

Conforme Mosimann e Fisch (1999) a controladoria tem por objetivo transmitir informaçóes para a tomada de decisóes, buscando efeitos positivos sobre suas áreas e sobre os aspectos econômicos, garantido a eficácia empresarial, levando em consideração que para ser útil, a informação deve ser confiável. 
Oliveira, Perez Jr. e Silva (2011), explicam que a controladoria é fundamental para o planejamento de longo prazo de qualquer organizaçáo, pois com a atual competitividade, globalização da economia, abertura de fronteiras comerciais, entre outros, é necessário um gerenciamento cada vez mais eficaz das entidades. Para contribuir com as demandas organizacionais, a controladoria deve exercer papel preponderante, fornecendo subsídios para os gestores no que condiz ao planejamento e controle de atividades operacionais, financeiras, comerciais, tributárias, etc., através da manutenção de sistemas de informaçôes que integrem diferentes funçôes e especialidades.

Oliveira, Perez Jr. e Silva (2011), aludem que a controladoria deve estar ligada aos sistemas de informação à gestão, tanto para as tarefas rotineiras quanto para as gerenciais e estratégicas. Os processos decisórios na área da gestão são influenciados pela controladoria, através das informaçôes de planejamento e controle. Essas informaçôes exigem sistemas capazes de suportar tais decisôes. Assim, a controladoria assessora a gestão e os processos de planejamento a fim de reportá-los as decisôes mais eficazes, aparecendo a figura do controller, aquele que no planejamento estratégico tem a função de auxiliar tanto o principal executivo quanto os demais gestores na busca de informaçôes rápidas, confiáveis e sensatas. (OLIVEIRA; PEREZ JR.; SILVA, 2011).

Assim, a controladoria atua em todas as áreas das organizaçôes coletando informaçóes e auxiliando nas tomadas de decisôes. Para isso, utiliza-se de algumas ferramentas, dentre elas o Balanced Scorecard.

\subsection{Balanced Scorecard (BSC)}

O controle financeiro, sempre foi utilizado como mecanismo fundamental para facilitar e monitorar a alocação de capital. Portanto, nas últimas décadas do século XX, o processo administrativo voltado somente para os relatórios financeiros mostrou-se inadequado, em virtude da existência de um paradigma ambiental de constante mudança, complexidade e incertezas. Uma empresa não sobrevive apenas com uma bela declaração de missão e valores, se estruturalmente a empresa não estiver direcionada para a obtenção dos objetivos traçados. (GALINDO, 2005).

Na busca de resultados mais satisfatórios, Kaplan e Norton no ano de 1992 apresentam o Balanced Scorecard (BSC), ferramenta capaz de traduzir a missão e a visão das organizaçóes em um conjunto amplo de medidas de desempenho que serve de base para um sistema de avaliação e gestão estratégica. (HERRERO FILHO, 2005).

Kallás (2005) menciona que o BSC é uma sigla que, traduzida, significa: indicadores balanceados de desempenho. Este é o nome de uma metodologia voltada à gestão estratégica das empresas. Tal metodologia pressupóe que a escolha dos indicadores para a gestão de uma empresa não deve se restringir a informações econômicas ou financeiras.

Para tanto, Kaplan e Norton (1997) consideram que o BSC é um sistema balanceado de gestão, pois promove o equilíbrio entre as seguintes variáveis estratégicas: objetivos de curto e longo prazos; entre foco interno e o ambiente externo da organização; e, entre os indicadores de ocorrência e de tendências.

Assim, como a própria estratégia competitiva, o conceito de BSC é dinâmico, estando em constante evolução. Sua metodologia procura traduzir a missão e a visão da empresa em medidas e objetivos capazes de refletir os interesses e expectativas de seus principais agentes (externos e internos), as quais são agrupadas 
em quatro perspectivas: financeira, do cliente, dos processos internos, e, da aprendizagem e crescimento. (HERRERO FILHO, 2005).

Para melhor entendimento e desenvolvimento do Balanced Scorecard (BSC), Kaplan e Norton (1997) destacam quatro perspectivas apresentadas pela metodologia do BSC, sendo a financeira, do cliente, dos processos internos e da aprendizagem e crescimento, conforme figura 1.

Figura 1 - Perspectivas do Balanced Scorecard

\section{As quatro perspectivas do Balanced Scorecard}

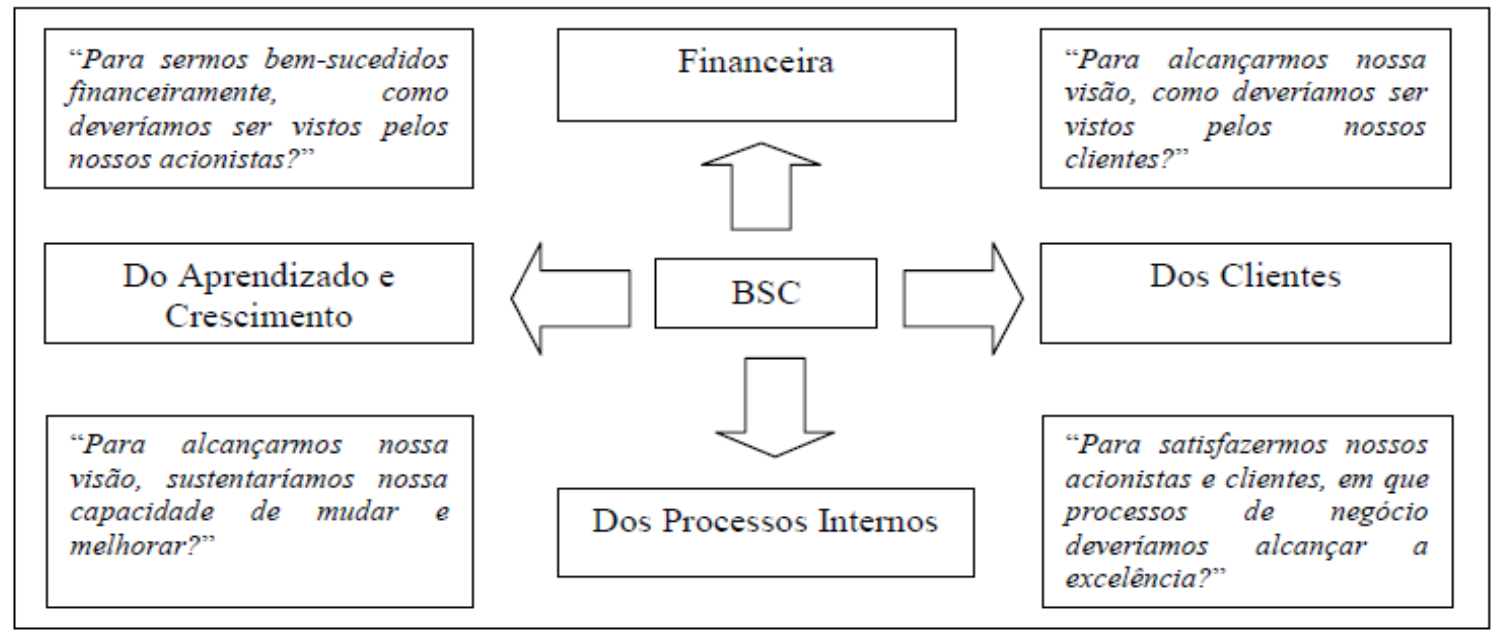

Fonte: Kaplan e Norton (1997, p. 10).

Essa metodologia é destacada por Herrero Filho (2005), como algo que traduz a missão e a visão da empresa em objetivos e estratégias, os quais reflitam os interesses e expectativas de seus agentes internos e externos.

Tais perspectivas, segundo Rampersad et al. (2004 apud BERNARDI et al. 2012), abrangem fatores como o sucesso financeiro, a liderança de mercado, fidelidade do consumidor, desenvolvimento de capital, domínio dos processos de negócios, entre outros.

a) Financeira: tem por objetivo, demonstrar se as escolhas estratégicas implementadas pela empresa estão contribuindo para a elevação do valor de mercado da organização, geração de valores econômicos além de propiciar aumento da riqueza dos acionistas e demais agentes externos, ou seja, seu foco principal está nos interesses dos acionistas de uma empresa. (HERRERO FILHO, 2005).

Nesse sentido, Tobias (2015) salienta que para definir os objetivos e indicadores dessa perspectiva é imprescindível responder a seguinte questão: para ser bem-sucedida financeiramente como a empresa deve aparecer perante seus acionistas? Para o autor, essa perspectiva influencia e é influenciada por outras perspectivas, fazendo com que os administradores intervenham mediante conhecimento dos indicadores para sugerir correçôes e alinhamento de objetivos.

Assim, de acordo com Herrero Filho (2005) os objetivos estratégicos dessa perspectiva, podem ser mensurados mediante utilização dos seguintes indicadores: Valor Econômico Agregado (EVA); Valor de Mercado Agregado (MVA); Retorno sobre o Investimento Base Caixa (CFROI); Retorno Total do Negócio (TBR); Retorno Total para o Acionista (TSR), e Valor Agregado Base Caixa (CVA). 
b) Do Cliente: Herrero Filho (2005), destaca que essa perspectiva, tem por objetivo mostrar se as escolhas estratégicas adotadas pela organização estão contribuindo para a elevação do valor percebido pelo cliente em relação a seus produtos, marcas, serviços, experiência de compra e relacionamentos.

Kaplan e Norton (1997) aludem que tal perspectiva deve centrar sua atenção na resposta da seguinte questão: para atingir a visão, como a empresa deve aparecer perante seus clientes? A empresa deve focar ao máximo no cliente para que ele não procure o concorrente, estando sempre atenta as suas expectativas, procurando surpreendê-los oferecendo continuamente produtos/serviços de qualidade e com variedade de preços.

Nesse sentido, a visão e satisfação do cliente frente ao estabelecimento estão diretamente relacionadas com a área financeira, pois qualquer fato negativo nesse ponto ocasiona redução do faturamento, uma vez que a sua existência gira em função de seus clientes (KAPLAN; NORTON, 1997).

Em uma sociedade marcada por grandes ofertas de produtos e serviços a diferenciação torna-se um desafio. A combinação de valores/preços, desempenho, qualidade, seleção e oportunidade tornam-se proposiçóes de valor, um dos elementos centrais na formulação da estratégia competitiva da empresa. (HERRERO FILHO, 2005).

Essas medidas, conforme Kaplan e Norton (1997) representam:

- Participação no mercado: é a proporção de vendas, determinada pelo número de clientes, capital investido e unidades vendidas ou instaladas;

- Retenção de clientes: percentual de clientes com o qual a empresa continua mantendo relaçóes comerciais;

- Captação de clientes: percentual de novos clientes ou negócios ganhos pela organização;

- Satisfação dos clientes: nível de satisfação dos clientes em relação aos critérios de desempenho ou valor agregado;

- Lucratividade do cliente: é a lucratividade do negócio medida após o levantamento das despesas necessárias para atender o cliente ou o mercado.

A gestão da criação de valor pelo cliente enfatizada por Herrero Filho (2005) deve merecer atenção total da equipe executiva, pois está no sucesso da perspectiva do cliente a geração do valor econômico agregado e o acréscimo de seu valor de mercado.

c) Dos Processos Internos: Essa perspectiva busca identificar se os principais planos traçados pela administração na busca da geração de valor econômico para o cliente, bem como para a empresa e acionistas está sendo implementada com sucesso, ou seja, é a fase da execução das estratégias. (HERRERO FILHO, 2005).

$\mathrm{Na}$ implementação do BSC, os processos internos desempenham três papéis relevantes, sendo: concentração nas iniciativas que viabilizem a proposição de valor ao cliente, contribuição na elevação da produtividade e geração de valor econômico agregado, e, indicação de novos conhecimentos e competências que a equipe precisa dominar para a geração de valor ao negócio. (HERRERO FILHO, 2005). 
d) Do Aprendizado e Crescimento: Esta perspectiva conforme Cardoso et al. (2012) deriva de três fontes fundamentais: pessoas, sistemas e procedimentos organizacionais. Tem por objetivo avaliar se o trabalho realizado pela equipe de executivos e colaboradores da organizaçáo está oportunizando a aprendizagem e criação de novos conhecimentos, que contribuirão para a criação de valor aos stakeholders. (HERRERO FILHO, 2005). Nesse sentido, Kaplan e Norton (1997) enfatizam que a perspectiva de aprendizagem e crescimento tem por objetivo inovar através de pessoas.

O questionamento que se busca responder nessa perspectiva, conforme Kaplan e Norton (1997) é: para alcançar a visão da empresa qual a disposição para mudanças e melhoras? Contudo, Herrero Filho (2005) reconhece que o fator mais importante para a sobrevivência e renovação das organizaçôes em suas atividades, éo individuo, tanto nas equipes de trabalho quanto nas áreas de negócio. Assim, reconhecendo-o mensura-se o seu valor mediante três formas integradas: o comportamento do empreendedor; a motivação frente ao aprendizado e gestáo do conhecimento; e a contribuiçáo para inovaçáo, renovação e crescimento da empresa.

Assim, se o Balanced Scorecard procura descrever a visão de futuro da organização, criando anseios e dando foco aos esforços de mudança, o mapa estratégico pode ser considerado como o pano de fundo, na qual a história da estratégia é narrada aos envolvidos com a empresa, fornecendo um novo referencial teórico e prático, numa cadeia de causa e efeito que vincula os resultados almejados com seus respectivos vetores. (HERRERO FILHO, 2005).

Através dessa ferramenta, é possível aos colaboradores da organização expandir sua área de visão, permitindo definir: os objetivos para o crescimento da receita nos mercados atuais, adjacentes e novos; inovação em valor, produtos, serviços e modelos de negócio que permitirão a sobrevivência e renovação; proposição de valor que permitirá a atração, retenção e fidelização dos clientes; investimento em capital humano, físico e na infra-estrutura de tecnologias da informação e comunicação. (HERRERO FILHO, 2005).

\section{METODOLOGIA}

Este estudo buscou determinar a influência no desempenho financeiro e organizacional do supermercado $\mathrm{X}$ através da perspectiva de seus clientes. A pesquisa pretende ainda identificar se existe influência dos preços cobrados na escolha de compra no supermercado.

Para atingir os objetivos do estudo foi utilizada a pesquisa de caráter descritivo, que segundo Diehl e Tatim (2004) tem por objetivo a descrição das características de determinada população ou estabelecimento de relaçáo entre as variáveis, possuindo como característica primordial a utilização de técnicas padronizadas para a coleta de dados, como o emprego de questionários. Assim, buscou-se identificar e avaliar as preferências dos consumidores do supermercado X, visando verificar se as escolhas estratégicas adotadas estão contribuindo para o aumento do valor percebido pelos clientes em relação aos produtos, serviços, imagem, relacionamento, entre outras.

Quanto à abordagem problemática, o estudo caracteriza-se como quantitativo, uma vez que se utiliza da identificação das preferências dos clientes para avaliação percentual das preferências e no cálculo dos indicadores financeiros em busca da resolução do problema pesquisado. Nos direcionamentos de 
Diehl e Tatim (2004) uma pesquisa de caráter quantitativo se estabelece quando se quantifica os dados coletados por meio de percentual, média, desvio padrão, dentre outros, possibilitando maior margem de segurança quanto às induçóes. (DIEHL; TATIM, 2004).

Utilizou-se o levantamento ou survey como procedimento técnico para o estudo. De acordo com Gil (2009) caracteriza-se pelo questionamento direto junto às pessoas cujo comportamento deseja-se avaliar, apresentando como vantagens a rapidez, economia e possibilidade de quantificação, além, do conhecimento direto da realidade. Neste estudo, foram identificadas as perspectivas dos clientes frente ao supermercado $\mathrm{X}$ e se as mesmas são atendidas.

$\mathrm{Na}$ pesquisa de levantamento foram aplicados questionários, com 100 clientes do supermercado $\mathrm{X}$, escolhidos aleatoriamente no período de 01 de abril a 30 de maio de 2015, obtendo-se a resposta de 75 deles. A amostra caracteriza-se como não probabilística, uma vez que segundo Diehl e Tatim (2004) são empregadas formas casuais de seleçáo, sendo que o entrevistador se dirige a elementos típicos da população que pretende examinar.

O questionário é composto de 17 questóes, dentre elas, uma aberta e 16 fechadas de múltipla escolha, que contemplam avaliaçáo dos motivos/preferências que levam os consumidores Ibiraiarenses a frequentar esse supermercado em detrimento de outros e quais suas perspectivas frente ao mesmo. Os dados foram analisados e interpretados através de elementos quantitativos mediante a participação percentual sobre o total coletado de cada questão, utilizando o Microsoft Excel e apresentando-se os resultados através de tabelas.

\section{APRESENTAÇÃO DOS RESULTADOS}

Neste tópico, serão apresentados os resultados obtidos com a aplicação de questionários juntos aos consumidores do Supermercado X. A análise procurou identificar os níveis de satisfação dos consumidores e quais os motivos que os levam a comprar ou deixar de comprar no supermercado, comparando-a com a gestão financeira e operacional do supermercado.

\subsection{Análise do Questionário}

A análise do questionário foi dividida em três blocos, sendo que o primeiro se dedicou à caracterização dos clientes do supermercado X, o segundo avaliou o nível de satisfação dos clientes em relação ao atendimento recebido ou percebido atualmente e por fim, no terceiro e último bloco buscou-se identificar a influência do preço e de outros atributos na decisão de compra dos consumidores.

\subsubsection{Caracterização dos clientes do Supermercado X}

Neste item buscou-se criar indicadores e caracterizar a clientela do Supermercado X. Dentre os itens analisados estão: sexo, frequência de visitação ao supermercado e se realiza compras em outros estabelecimentos. Os dados estão apresentados na Tabela 1. 
Tabela 1 - Clientes do Supermercado X

\begin{tabular}{l|c}
\hline $\mathbf{1}$ - Gênero & Frequência relativa (\%) \\
\hline a) Masculino & 6,66 \\
\hline b) Feminino & 93,34 \\
\hline $\mathbf{2}$ - Quantas vezes por mês você frequenta o Super X? & 0 \\
\hline a) 1 vez & 0 \\
\hline b) 2 vezes & 14,67 \\
\hline c) Semanalmente & 85,33 \\
\hline d) Várias vezes, sempre que precisar & \\
\hline 3 - Você frequenta somente o Super. X, ou outros? & 49,33 \\
\hline a) Somente o Super. X & 50,67 \\
\hline b) Outros supermercados & 6,67 \\
\hline 4- A quantos anos vocé é cliente do Super. X? & 12,00 \\
\hline a) 1 ano & 17,33 \\
\hline b) 1 a 3 anos & 10,67 \\
\hline c) 4 a 6 anos & 53,33 \\
\hline d) 7 a 9 anos & $\mathbf{1 0 0 , 0 0}$ \\
\hline e) mais de 10 anos & \\
\hline Total & \\
\hline
\end{tabular}

Na tabela 1 identificam-se as características dos clientes do Supermercado X. Observa-se por meio dela que dos clientes respondentes, a população feminina é a que mais o frequenta, com uma participação percentual de $93,34 \%$, contra $6,66 \%$ da masculina.

Quanto à frequência de idas ao supermercado, é notável que 85,33\% da população consumidora, optam por fazê-la sempre que houver necessidade de comprar, não havendo um planejamento. Já 14,67\% dos clientes preferem frequentar o supermercado semanalmente.

Em pesquisa realizada anteriormente no Supermercado X no ano de 2012, identificou-se que os consumidores frequentavam o estabelecimento poucas vezes, normalmente uma vez por mês e faziam o "rancho" mensal. Logo, essa vinda assídua proporciona o acesso a mercadorias mais recentes e a compra de produtos necessários para a semana, e permite que os consumidores aproveitem promoçóes que são dispostas toda a semana, além das ofertas de frutas e verduras nos finais de semana. As promoçóes não são divulgadas, sendo que para saber sobre as mesmas, os clientes precisam se deslocar até as dependências do supermercado. Para o estabelecimento, esta mudança na frequência acarretou no aumento das receitas, pois indo mais vezes os clientes acabam comprando mais.

Em um ambiente de acirrada competição, quando questionados pela exclusividade de compra no Supermercado X, as respostas se dividiram, apresentando que 50,67\% consomem nos demais cinco supermercados da cidade, enquanto 49,33\% disseram serem clientes exclusivos do supermercado X.

Em relação ao tempo que é cliente do Supermercado X, constatou-se que 53,33\% dos pesquisados são clientes fieis e realizam suas compras nele a mais de 10 anos. Já 28\% frequentam o supermercado de 4 a 9 anos, 18,67\% são clientes recentes e manifestam que frequentam o supermercado de 0 a 3 anos. Percebe-se, que o supermercado além possuir clientes fidelizados vem atraindo novos clientes ao seu negócio. 


\subsubsection{Avaliação do atendimento do Supermercado X}

Neste bloco os clientes foram questionados sobre porque escolhem o supermercado X para realizar suas compras. Também foram solicitados a esclarecerem os motivos que os levam a deixar de comprar no Supermercado X. Dentre os itens analisados estão: atendimento por seção e seçôes que não atendem as necessidades dos clientes, conforme, apresenta-se na Tabela 2:

Tabela 2 - Avaliação do atendimento do Supermercado X

\begin{tabular}{|c|c|}
\hline 5 - Por qual razão você frequenta Super. $X$ & $\begin{array}{c}\text { Frequência } \\
\text { Relativa }(\%)\end{array}$ \\
\hline a) Atendimento & 5,33 \\
\hline b) Melhores preços & 0,00 \\
\hline c) Qualidade dos produtos & 44,00 \\
\hline d) Variedade dos produtos & 1,33 \\
\hline e) Condições de pagamento & 0,00 \\
\hline f) Localização & 0,00 \\
\hline g) Todos os itens acima & 49,34 \\
\hline \multicolumn{2}{|l|}{6 - Por qual razão você deixa de frequentar o Super. $X$} \\
\hline a) Atendimento & 5,33 \\
\hline b) Preços & 33,33 \\
\hline c) Qualidade dos produtos & 4,00 \\
\hline d) Variedade dos produtos & 9,34 \\
\hline e) Condições de pagamento & 4,00 \\
\hline f) Localização & 0,00 \\
\hline h) Somente frequenta o Super. $X$ & 44,00 \\
\hline \multicolumn{2}{|l|}{7 -Quanto ao atendimento, qual o departamento que melhor the atende } \\
\hline a) Açougue & 28,00 \\
\hline b) Lanchonete & 9,33 \\
\hline c) Fruteira & 0,00 \\
\hline d) Caixas & 0,00 \\
\hline e) Todos & 62,67 \\
\hline \multicolumn{2}{|l|}{8 -Quanto ao atendimento, qual 0 departamento que deve melhorar 0 atendimento } \\
\hline a) Açougue & 0,00 \\
\hline b) Lanchonete & 12,00 \\
\hline c) Fruteira & 13,33 \\
\hline d) Caixas & 28,00 \\
\hline e) Nenhum, todos possuem bom atendimento & 46,67 \\
\hline \multicolumn{2}{|l|}{9 - Qual o departamento em sua opinião the atrai a fazer suas compras } \\
\hline a) Açougue & 24,00 \\
\hline b) Padaria & 50,67 \\
\hline c) Lanchonete & 18,67 \\
\hline d) Bazar & 0,00 \\
\hline e) Fruteira & 6,67 \\
\hline \multicolumn{2}{|l|}{10 - Qual o departamento em sua opinião merece ser melhorado } \\
\hline a) Açougue & 2,67 \\
\hline
\end{tabular}




\begin{tabular}{l|c}
\hline b) Padaria & 9,33 \\
\hline c) Lanchonete & 10,67 \\
\hline d) Bazar & 40,00 \\
\hline e) Fruteira & 20,00 \\
\hline f) Nenhum & 17,33 \\
\hline Total & $\mathbf{1 0 0 , 0 0}$ \\
\hline
\end{tabular}

Através da tabela 2, apresenta-se a avaliação do atendimento prestado pelo supermercado $\mathrm{X}$ pelas respostas de seus clientes. Quando questionado sobre quais razóes os levam a frequentar o estabelecimento, mais de $49 \%$ dos clientes relatam que é o conjunto completo do Supermercado X, representado pelo atendimento, localização, preço, qualidade entre outros atributos.

Porém ressalta-se que 44\% dos clientes do supermercado X, informam que frequentam o mercado por encontrarem a qualidade dos produtos de acordo com o desejado. Nesta questão, bem como em outras do estudo, mesmo que as alternativas fossem fechadas, os clientes acabaram fazendo anotaçóes no questionário, e relacionaram a qualidade com a aparência dos produtos, sua forma, seu processo de fabricação, sua durabilidade, entre outros.

$\mathrm{Na}$ lanchonete e na padaria, a qualidade está relacionada aos assados, os quais náo possuem gosto de fritura, não são gordurosos, são bem cozidos e ou assados. Relatam que a qualidade dos produtos se dá, porque os sucos e cafés possuem um sabor próprio do ingrediente utilizado. De acordo com relatos dos clientes no formulário, no açougue, as carnes são macias, apresentam cor e cozimento adequados e os embutidos são bem temperados. Outros $6 \%$ destacam a variedade dos produtos e o atendimento.

Quando indagados sobre os motivos que os levam a deixar de realizar suas compras no supermercado X, 44\% destacam que realizam suas compras somente neste estabelecimento. Já para 33,33\% o motivo está no preço praticado, o que explica a razão pelo qual mais da metade dos entrevistados fazem parte de suas compras também nos estabelecimentos concorrentes.

O fator preço é para os consumidores um determinante importante na decisão de compra. Quando oscilante em relaçáo ao mesmo produto, o consumidor além de considerar a qualidade do mesmo, procura adquirir aquele que cabe no seu orçamento, na grande maioria, o de menor preço.

Nesse sentido, Zanon (apud FIGUEIREDO, 2014) ressalta que o preço é um fator importante para o varejista se posicionar no mercado de forma mais competitiva, no entanto, o consumidor busca primeiramente o produto, serviço, atendimento e, somente após isso, um preço justo que ele esteja disposto a pagar ou que irá agregar valor ao produto. Isso fica claro no Supermercado X o qual é identificado por seus clientes através da qualidade dos produtos.

No que tange ao atendimento os clientes foram questionados sobre quais dos departamentos que melhor o fazem. Para $62,67 \%$ todos os departamentos possuem um bom atendimento, o que não se sucede para $28 \%$ dos pesquisados, que salientam que é no açougue que encontram o melhor atendimento. Segundo os respondentes, o bom atendimento foi interpretado quanto á disposição dos atendentes em oferecer, mostrar e conhecer o produto que está sendo vendido, praticar diálogo. Outros 9,33\% dos consumidores indicam o atendimento da lanchonete como o melhor, pois o atendimento é feito com cordialidade, disposição e bom humor. Os departamentos: fruteira e caixas não receberam indicações. 
No interesse de saber se o atendimento não é prestado como deveria ser, foi indagado ao pesquisados qual o departamento que merece melhorá-lo. As indicaçóes foram feitas para três deles na seguinte colocação: $28 \%$ destacam que é nos caixas, sendo que os clientes relataram no formulário que o atendimento é deficitário, e que alguns caixas não possuem a cordialidade desejada. Para 13,33\% dos clientes é na fruteira e 12\% na lanchonete, sendo que nesta os clientes descrevem que o problema ocorre pela falta de pessoas para prestar o atendimento. Apesar dessas colocações, 46,67\% dos clientes estão satisfeitos com o atendimento de todos os departamentos do supermercado X, náo indicando nenhum para melhoria. Este item identificou problemas pontuais para os quais a direção do Supermercado X deverá encontrar soluçóes.

Quando questionados sobre qual o departamento que mais os atrai ao supermercado X, os clientes destacaram a padaria, com $50,67 \%$ das indicaçóes, descrevendo no formulário, que é a melhor por possuir uma variedade satisfatória de alimentos, os quais apresentam um sabor inigualável quando comparado aos demais estabelecimentos da cidade, em seguida o açougue com $24 \%$, a lanchonete com $18,67 \%$ e por último a fruteira, para $6,67 \%$ dos entrevistados.

$\mathrm{Na}$ intenção de conhecer quais os departamentos que merecem ser melhorados e o sentido dessa melhoria, constatou-se que o departamento bazar foi o mais indicado com $40 \%$ das intençóes. Esta questão era aberta, e o cliente foi questionado sobre o que era necessário melhorar, sendo assim, relataram que os produtos devem ser organizados e dispostos de melhor forma permitindo sua visualização e ainda ressaltam que gostariam de uma maior variedade, em especial na linha de brinquedos.

Com 20\% das indicaçóes, a fruteira segundo clientes deve dispor de maior espaço para circulaçáo de pessoas/carrinhos e maior variedade em ofertas de frutas, legumes e cereais da regiáo.

A lanchonete também recebeu indicação de pelo menos 10,67\% dos clientes, que salientam que a mesma deve oferecer maior agilidade no atendimento, além, de lanches mais saudáveis inclusive para crianças. Logo, na padaria com sugestão de $9,33 \%$ dos clientes, deve produzir os alimentos com recheio de produtos naturais e saudáveis, e dispor de mais assados em detrimento a frituras. Já 17,33\% dos entrevistados apontaram que nenhum departamento necessita de melhorias.

\subsubsection{Avaliação do preço e satisfação dos clientes do Supermercado X}

Neste bloco os clientes foram questionados sobre sua satisfação em relação ao supermercado X, quanto às mercadorias disponibilizadas, preço dos produtos e principalmente quanto ao grau de satisfação com o supermercado. Os dados estão apresentados na Tabela 3:

Tabela 3 - Avaliação da Satisfação dos clientes

\begin{tabular}{l|c}
\hline 12 - Na hora das compras, você encontra todas as mercadorias desejadas & $\begin{array}{c}\text { Frequência } \\
\text { Relativa }(\%)\end{array}$ \\
\hline a) Sim & 25,33 \\
\hline b) Não & 13,33 \\
\hline c) Na maioria das vezes & 61,33 \\
\hline 13 - Você leva em consideração o "preço do produto" na hora da compra & 32,00 \\
\hline a) Sim & 16,00 \\
\hline b) Não & \\
\hline
\end{tabular}




\begin{tabular}{l|c}
\hline c) Comparo preço e qualidade & 52,00 \\
\hline $\mathbf{1 4}$ - Os preços praticados pelo Super. X estão dentro de suas condições & 32,00 \\
\hline a) Sim & 0,00 \\
\hline b) Não & 64,00 \\
\hline c) Na maioria das vezes & 4,00 \\
\hline d) Não respondeu & 2,67 \\
\hline 15 - Qual sua atitude quando fica INSATISFEITO com os produtos/serviços \\
prestados pelo Super. X
\end{tabular}

Pela tabela 3 avaliou-se o supermercado X no quesito preço e satisfação. Assim, 61,33\% dos entrevistados alegaram que na maioria das vezes encontram todas as mercadorias de que necessitam. Já $25,33 \%$ assinalaram que sim, na hora das compras conseguem todos os produtos, sem a necessidade de procurá-lo no concorrente. Mas para 13,33\% dos consumidores isso náo ocorre, levando-os a frequentar outros estabelecimentos ou aguardando o produto, em razão do Supermercado $\mathrm{X}$ não o dispor no momento da demanda.

Considerando o fator preço como um determinante no momento da compra, quando questionado aos clientes se ele é significante na aquisição ou não do produto, conclui-se que $52 \%$ dos consumidores questionados comparam preço e qualidade, ou seja, se a qualidade do produto é o diferencial e está aliado ao preço justo. Já para 32\% dos clientes, o fator relevante é o preço, se o mesmo for considerado alto, o produto não é adquirido; mas para $16 \%$ dos clientes, o preço do produto não é levado em consideração no momento da compra.

Quando questionado se os preços praticados pelo supermercado X estavam dentro das condiçóes de seus clientes, $64 \%$ destes assinalaram que "na maioria das vezes" e outros $32 \%$ alegam que sim. Desse modo, é possível destacar que o supermercado X trabalha com bons fornecedores o que torna possível a prática de margens de lucro sobre os produtos que condizem com as condiçôes econômicas de seus consumidores, sem comprometer seu resultado e sua carteira de clientes. Os que não responderam, somaram $4 \%$. 
$\mathrm{Na}$ intenção de conhecer a atitude do cliente quando ao encontrar um produto ou serviço que não lhe satisfaça, identificou-se que $44 \%$ destes mesmos insatisfeitos com aquilo que encontraram, voltam a frequentar o estabelecimento normalmente, talvez por falta de um estabelecimento melhor na cidade. Os demais clientes responderam que reclamam, devolvem o produto e somente $3 \%$ alegam que trocariam de estabelecimento.

Devido à grande concorrência, nem sempre é fácil reter clientes, então, é preciso por parte das empresas uma gestão eficiente e proativa do relacionamento e das interaçôes com os mesmos. (RIECHELMANN, 2012). Nesse contexto, quando indagados se estavam gostando de fazer suas compras no estabelecimento, a aprovação se deu pela totalidade dos clientes, que ao atribuir uma nota de 5 a 10 para o supermercado X, as respostas se deram nas seguintes proporçóes: $73 \%$ conferiram nota de 9 a 10 ; $27 \%$ atribuíram a nota 8 .

\subsection{Avaliação do Desempenho Financeiro do Supermercado X através da Perspectiva do Cliente}

Essa avaliação fora feita em dois momentos. Primeiramente foi entregue um questionário junto aos clientes do supermercado X, visando identificar suas perspectivas quanto á satisfação dos produtos disponíveis por meio de sua qualidade, atendimento prestado e preço praticado.

Com isso, foi possível notar que o supermercado possui clientes fidelizados, os quais o acompanham a mais de dez anos, razão esta que se explica pela qualidade dos produtos comercializados. Identificouse também que a padaria é responsável por mais de 50\% das indicaçóes positivas do supermercado, por dispor de lanches e demais alimentos prontos que vão ao encontro das necessidades dos clientes e apresentam fabricação adequada ao exigido e ao paladar do consumidor. Após, fora realizado uma análise das demonstraçóes contábeis e o cálculo de alguns índices para um período de quatro anos, evidenciando giro do estoque, prazos de pagamento e recebimento, taxas de retorno sobre o ativo e patrimônio líquido.

Verificou-se a partir dessa análise, que com a implantação de um negócio anexo, denominado X Café, o supermercado obteve elevação da rentabilidade, além de trazer mais consumidores para seu estabelecimento, proporcionando maior giro de estoque e consequentemente maior faturamento.

Uma das evidências que este estudo observou é de que o preço dos produtos não define a preferência por um supermercado, isto fica claro quando $68 \%$ dos clientes evidenciam que buscam sim melhor preço, mas analisam também a qualidade.

A qualidade é um dos investimentos ou uma das estratégias do Supermercado X, na medida em que as carnes são selecionadas, as frutas e verduras são sempre frescas e bem selecionadas. Isso atrai os clientes, que sabem que de nada adianta comprar uma fruta ou verdura mais barata, e no dia seguinte ter que colocar no lixo, pois as mesmas apodreceram.

A satisfação e a fidelização de clientes viabilizam um fluxo de caixa contínuo ao longo prazo, visto que clientes satisfeitos compram os produtos com mais frequência e em maior quantidade. De modo geral, a satisfação torna-os menos sensíveis a preços e propensos a gastar mais. 
Em relação ao quesito investimentos, verifica-se também retornos, visto com a ampliação em 2011 e a abertura do X Café, tanto a receita como a lucratividade do supermercado ampliaram, pois proporcionou-se maior comodidade ao consumidor.

Através da realização desta pesquisa observou-se como é importante a percepção que os clientes têm do estabelecimento e seu impacto no desempenho financeiro. Dessa forma, é importante que o supermercado X, continue a ouvir as consideraçôes de seus clientes, através da colocação de softwares na entrada do supermercado, ou mesmos de estagiários que apliquem na entrada e saída às questôes, através da entrega de um formulário a ser colocado em urna e ou até mesmo no site, ou por e-mail.

É importante que a pesquisa seja breve, e assim os indicadores devem ser medidos de forma alternada, para que se obtenha maior participação dos clientes, ressaltando que o número máximo de questóes a ser aplicado é de cinco por avaliação. Os indicadores identificados são:

- Qualidade e variedade de produtos;

- Apresentação e reposição eficiente dos produtos;

- Atendimento;

- Opçóes e prazos de pagamento;

- Promoções;

- Setores que necessitam de melhorias;

- Setor (es) de destaque;

- Inovação e lançamentos de produtos (padaria);

- Avaliação do tempo de permanências em filas;

- Localização, estacionamento;

A partir de 2015, a empresa conta com um sistema de avaliação gerencial do resultado por departamento. Dessa forma, no intuito de avaliar a perspectiva dos clientes com o retorno financeiro, apresenta-se na tabela 7 os resultados dos departamentos mencionados pelos clientes como aqueles que os atraem para realização de compras e frequência ao supermercado.

Tabela 7 - Resultado por departamento

\begin{tabular}{l|c|c|c|c|c|c|c|c}
\hline \multicolumn{1}{c|}{ Departamentos } & Açougue & $\mathbf{\%}$ & Fruteira & $\mathbf{\%}$ & Padaria & $\mathbf{\%}$ & $\begin{array}{c}\text { Mercearia } \\
\text { e outros }\end{array}$ & \% \\
\hline Receita Bruta & $\mathbf{8 4 8 . 2 6 8}$ & & $\mathbf{2 3 2 . 2 6 8}$ & & $\mathbf{6 0 8 . 8 9 6}$ & & $\mathbf{2 . 1 1 5 . 4 9 8}$ & \\
(-) Impostos s/Venda & 15.365 & & 172 & & 39.349 & & 1.621 .68 & \\
Receita Líquida & $\mathbf{8 3 2 . 9 0 3}$ & $\mathbf{1 0 0}$ & $\mathbf{2 3 2 . 0 9 6}$ & $\mathbf{1 0 0}$ & $\mathbf{5 6 9 . 5 4 7}$ & $\mathbf{1 0 0}$ & $\mathbf{1 . 9 5 3 . 3 3 0}$ & $\mathbf{1 0 0}$ \\
CMV + Perdas & 586.072 & 70,36 & 143789 & 61,95 & 231.038 & 40,57 & 1.188 .247 & 60,83 \\
Resultado Bruto & $\mathbf{2 4 6 . 8 3 1}$ & 29,64 & $\mathbf{8 8 . 3 0 7}$ & $\mathbf{3 8 , 0 4}$ & $\mathbf{3 3 8 . 5 0 9}$ & $\mathbf{5 9 , 4 3}$ & $\mathbf{7 6 5 . 0 8 3}$ & $\mathbf{3 9 , 1 7}$ \\
Despesas Operacionais & 189.882 & 22,80 & 41798 & 18,00 & 248.631 & 43,65 & 230.220 & 11,79 \\
\hline Resultado & $\mathbf{5 6 . 9 4 9}$ & $\mathbf{6 , 8 4}$ & $\mathbf{4 6 . 5 0 9}$ & $\mathbf{2 0 , 0 3}$ & $\mathbf{8 9 . 8 7 8}$ & $\mathbf{1 5 , 7 8}$ & $\mathbf{5 3 4 . 8 6 3}$ & $\mathbf{2 7 , 3 8}$ \\
\hline
\end{tabular}

Fonte: Controle Interno Supermercado X (2015). 
De acordo com o questionário, ao perguntar aos clientes qual o departamento que os atraia a realizar suas compras, mais de $50 \%$ das respostas indicaram a padaria, $24 \%$ o açougue e $7 \%$ a fruteira. Pela tabela 7, observa-se que a margem de lucro bruto da padaria é de $59 \%$, do açougue $30 \%$ e da fruteira $38 \%$. De modo que a preferência enfatizada pelos clientes reflete diretamente no resultado financeiro, é possível concluir que esses departamentos estáo atendendo de forma satisfatória as necessidades dos clientes e tal satisfação é refletida no resultado bruto de cada departamento.

Desse modo, é importante que a direção do supermercado X controle as despesas operacionais de cada departamento e assim alcance a otimização do resultado final.

Assim, é evidente que em um negócio de elevada concorrência, a fidelidade é responsável pela permanência do negócio, e seu resultado é refletido diretamente no faturamento, sendo, o conhecimento das expectativas dos clientes um fator necessário quando o interesse é agregar valor.

\subsection{Recomendaçôes e sugestôes}

Com base nos dados observados e mencionados, foi possível obter as informaçóes relevantes do supermercado X, através destas, recomendam-se algumas alteraçôes e sugestôes de procedimentos de controles internos. Tais pontos poderão melhorar e ou incrementar os controles já existentes na organizaçáo, e que proporcionarão maior segurança aos processos, controles e saúde do negócio.

Como salientado nos indicadores, o supermercado está pagando seus fornecedores antes de receber de seus clientes, o que acarreta maior necessidade de capital de giro. Para tal, sugere-se que essa prática seja revista com prioridade, atentando para a negociaçáo de maiores prazos com os fornecedores e a cobrança da cartela de clientes seja efetuada em um período menor, obtendo-se folga financeira.

A análise financeira permitiu verificar que nos últimos anos as devoluções de vendas apresentaram evoluçôes constantes e de grande magnitude. Assim, sugere-se que a administração do supermercado reveja essa permissão para a devolução, pois muitas vezes são efetuadas por motivos supérfluos e por descuidos em razão da falta de atenção de sua equipe de colaboradores.

Atualmente o supermercado X possui como opçóes de recebíveis: dinheiro, cheque e cartáo. Em razão de possuir $53 \%$ de clientes que o frequentam a mais de dez anos e $49 \%$ que são seus clientes exclusivos, sugere-se a criação de um cartão fidelidade para tais clientes oferecendo em troca descontos á partir do acumulo de pontos, entre outros.

Realizar estudos, objetivando chegar a uma porcentagem mais aproximada possível do custo operacional para cada departamento, viabilizando a prática de menores preços para atingir melhores resultados, pois segundo pesquisa junto aos clientes ficou claro que $33 \%$ deles muitas vezes frequentam o concorrente para buscar melhores preços.

$\mathrm{O}$ questionamento aos clientes deixou evidente que o atendimento em determinados setores do supermercado, em especial aquele prestado nos caixas precisa ser melhorado, pois algumas atendentes são desprovidas da cordialidade desejada. Assim, recomenda-se disponibilizar de treinamentos aos colaboradores, na questão atendimento. 
Maira Sgarbossa | Mirna Muraro

Quanto às melhorias setoriais, apresentou-se o departamento do bazar e da fruteira para recebê-las. $\mathrm{Na}$ visão dos clientes, ambos são de pequena extensão o que dificulta a exposição das mercadorias e por consequência sua visualização. É fundamental a reversão dessa realidade, em razão do bazar possibilitar a prática de excelentes margens de lucro e a fruteira, ser isenta de tributaçáo, o que garante maior lucratividade e apreciação pelo seu sabor natural.

No quesito insatisfação, verificou-se que quando o cliente não aprova os produtos ou serviços prestados, 44\% deles continuam a frequentar o supermercado. Essa situação precisa ser tratada com atençáo, uma vez que isso ocorre por não existir um segundo ponto de compra, o que "obriga" o consumidor a "aceitar" aquilo que tem.

\section{CONSIDERAÇÕES FINAIS}

Uma empresa se torna competitiva quando se diferencia por seus preços ou apresenta significativas melhorias nos seus produtos e serviços em torno de determinado público-alvo.

Nos últimos tempos, a competição entre as organizaçóes está cada vez mais acirrada, principalmente, no setor supermercadista, em que opções de escolha para os consumidores não faltam. Para atender de forma efetiva e alcançar melhor os resultados, o supermercado tem que identificar em quais aspectos precisa melhorar e adequar.

Esta pesquisa teve com o objetivo verificar se o desempenho financeiro e organizacional do supermercado X pode ser avaliado e mensurado através da perspectiva de seus clientes. Observou-se, através da aplicação do questionário junto aos clientes, que suas percepçôes possuem forte influência no seu desempenho, principalmente financeiro. Marcado pela participação de quase $94 \%$ da clientela feminina, que frequenta o estabelecimento várias vezes ao mês a fim de suprir necessidades, faz com que a preocupaçáo com variedade e qualidade de produtos/serviços seja tratada com atençáo especial, uma vez que a população feminina é mais detalhista e exigente.

Verificou-se, que o supermercado possui mais de 53\% de clientes fidelizados que o frequentam, pois sabem que os produtos comercializados são de qualidade, conforme aponta $44 \%$ dos entrevistados, que não levam em conta somente o preço na hora da compra.

Apesar da qualidade que atrai, os preços praticados sobre as mercadorias são responsáveis pela indicação de 33\% dos clientes, como motivo para deixar de fazer suas compras no supermercado X e procurar os concorrentes.

Por possuir uma variedade satisfatória de alimentos, cuja qualidade é percebida e reconhecida pelos clientes, a padaria, destaca-se na visão de mais de 50\% dos clientes como o departamento responsável pelas várias idas ao supermercado durante mês. Com a construção da lanchonete e abertura de um negócio anexo "X Café" o desempenho financeiro tornou-se ainda melhor, uma vez que além da qualidade, proporcionou-se um espaço de ampla comodidade.

$\mathrm{O}$ estudo centrado nas perspectivas dos clientes do supermercado $\mathrm{X}$ permitiu alcançar os objetivos pretendidos pelo estudo, pois identificou que os clientes reconhecem, percebem e valorizam os investimentos realizados pelo Supermercado X, em estrutura, organização e qualidade. Ainda importante 
destacar que a empresa deverá sempre aperfeiçoar aquilo que já é de agrado ao cliente, sendo este um compromisso conjunto da administração e colaboradores do supermercado, buscando satisfação do consumidor e a prosperidade do negócio.

Contudo, este estudo contribuiu para evidenciar as necessidades e satisfaçóes dos clientes do supermercado X, a fim de explicitar que as escolhas implementadas estão contribuindo para o aumento do valor percebido pelos clientes em relação aos produtos, serviços, imagem, marca, experiência de compra e relacionamento, produzindo reflexos positivos no desempenho financeiro dos departamentos e no negócio como um todo. Além disso, contribuiu para o levantamento e conhecimento de indicadores cujo monitoramento, contribui para alavancar as atividades em busca da eficácia dos resultados e processos e de departamentos tidos como preferenciais em razão de sua qualidade percebida tanto nos produtos quanto no atendimento.

\section{REFERÊNCIAS}

BERNARDI, Talita; SILVA, Iris B. da; BATOCCHIO, Antonio. Roteiro para implantaçáo de Balanced Scorecard: estudo de caso em pequena empresa. Revista de Ciência \& Tecnologia, Campinas, v. 17, n. 33, p. 87-102, jan. jun. 2012. Disponível em: <https:/www.metodista.br/revistas/revistasunimep/index.php/cienciatecnologia/article/viewFile/1044/679>. Acesso em: 13 nov. 2014.

CARDOSO, Bianca M. F.; RODRIGUES, Fernanda; VERÍSSIMO, João P. A. S.; ESTEVES, Marcos A. R.; HOVITA, Ricardo Y.; SILVA, Heloisa H. R. Aplicaçáo do Balanced Scorecard como sistema de alinhamento ao planejamento estratégico. Revista Científica do Unisalesiano - Lins. São Paulo, v. 3, n. 7, p. 182-196, jul. dez. 2012. Disponível em: <http://www.salesianolins.br/universitaria/artigos/ no7/artigo12.pdf>. Acesso em: 12. Jan. 2015.

CUNHA, Bethânia C.; SANTOS, Ariane C. P. Importância da controladoria na empresa. Minas Gerais, p. 1-19, 09 dez. 2013. Disponível em: <http://www.estudantesdeadm.com/news/importânciada-controladoria-na-empresa/>. Acesso em: 17 dez. 2014.

DIEHL, Antônio; TATIM, Denise Carvalho. Pesquisa em ciências sociais aplicadas: métodos e técnicas. São Paulo: Prentice Hall, 2004.

FIGUEIREDO, Nayara. Vai um desconto aí. Revista Decnews. Esteio, n 38, p. 32-33, set/out 2014.

FREZATTI, Fábio; GUERREIRO, Reinaldo; AGUIAR, Andson B. de. Diferenciaçóes entre a contabilidade financeira e a contabilidade gerencial: uma pesquisa empírica a partir de pesquisadores de vários países. Revista Contabilidade Financeira - USP. São Paulo, n. 44, p. 9-22, maio/agosto 2007. Disponível em: <http://www.scielo.br/pdf/rcf/v18n44/a02v1844.pdf>. Acesso em: 20. mar. 2015.

GALINDO, Alexandre G. Balanced Scorecard como sistema de alinhamento e controle estratégico da gestáo. In: Simpósio de Excelência em Gestão e Tecnologia - SEGeT - ADEB. II. Anais... Resende - RJ. 2005. p. 57-71. Disponível em: <www.ceap.br/artigos/ART27082009162935.pdf>. Acesso em: 27 dez. 2014.

GIL, A. C. Como elaborar projetos de pesquisa. 4. ed. São Paulo: Atlas, 2009. 
Maira Sgarbossa | Mirna Muraro

GRZESZEZESZYN, Gilberto. Contabilidade gerencial estratégica: conceito e caracterização. Revista Capital Científico, Guarapuava - PR. v. 1, n. 3, p. 9-27, jan./dez. 2005. Disponível em: <http://200.201.10.18/index.php/capitalcientifico/article/view/607>. Acesso em: 20 mar. 2015.

HERRERO FILHO, Emílio. Balanced Scorecard e a gestáo estratégica: uma abordagem prática. 2. ed. Rio de Janeiro: Elsevier, 2005.

KALLÁS, David. O que é Balanced Scorecard. 2005. Disponível em: <http://www.mppr.mp.br/ arquivos/File/o_que_e_bsc.pdf>. Acesso em: 09 fev. 2015.

KAPLAN, Robert S.; NORTON, David P. A Estratégia em Açáo: Balanced Scorecard. 10. ed. Rio de Janeiro: Campus, 1997.

KRAEMER, Maria E. P. O impacto do balanced scorecard na contabilidade gerencial. Revista de Contabilidade Vista e Revista, Dep. de Ciências Contábeis da Faculdade de Ciências Econômicas UFMG, Belo Horizonte, v. 13, n. 3, p. 53-70, dez. 2002. Disponível em: <https://revistas.face.ufmg.br/ index.php/contabilidadevistaerevista/article/view/204>. Acesso em: 14 fev. 2015.

KRAEMER, Maria E. P. Sistema de gerenciamento estratégico: Balanced Scorecard - nas instituiçóes de ensino superior. p. 1-23, mar. 2005. Disponível em: <http://www.gestiopolis.com/Canales4/ger/ sistemageren.htm>. Acesso em: $21 \mathrm{dez} .2014$.

MENEZES, Valdelício. A contabilidade gerencial e sua impotância na atualidade. Paraná p. 1-5, set. 2010. Disponível em: <http://www.administradores.com.br/artigos/carreira/a-contabilidade-gerencial-esua-importancia-na-atualidade/47936/>. Acesso em: 17 fev. 2015.

MOSIMANN, Clara P.; FISCH, Sílvio. Controladoria: seu papel na administração de empresas. 2. ed. São Paulo: Atlas, 1999.

NASCIMENTO, Luiz Gustavo; CAVENAGHI, Vagner. Balanced Scorecard: proposta de mapa estratégico para empresas de callcenter. In: Congresso Nacional de Excelência em Gestáo Responsabilidade Socioambiental das Organizaçóes Brasileiras, IV, 2008, Niterói. Anais... Niterói. 2008. p. 1-25. Disponível em: <http://www.latec.uff.br/cneg/documentos/anais_cneg4../T7_0096_0265. pdf>. Acesso em: 18 dez. 2014.

OLIVEIRA, Luís Martins de; PEREZ JR, José Hernandez; SILVA, Carlos Alberto dos Santos. Controladoria estratégica: textos e casos práticos com solução. 8. ed. São Paulo: Atlas, 2011.

PADOVEZE, Clóvis Luiz. O papel da Contabilidade Gerencial no processo empresarial de criação de valor. Cad. estud. [online]. 1999, n. 21, p. 01-16. Disponível em: <http:/www.scielo.br/pdf/cest/ n21/n21a03.pdf>. Acesso em: 17 jan. 2015.

RIECHELMANN, Ederson. Para ter fidelidade, mantenha o seu cliente satisfeito. 2012. Disponível em: <http://webinsider.com.br/2012/10/31/para-ter-fidelidade-mantenha-o-seu-cliente-satisfeito/>. Acesso em: 01 jun. 2015. 
ROCHA, Irani; LAVARDA, Carlos E. F. Balanced Scorecard (bsc) como instrumento de planejamento e controle empresarial. p. 1-16. 2009. Disponível em: <http://www.ead.fea.usp.br/ semead/12semead/resultado/trabalhosPDF/601.pdf>. Acesso em: 20 dez. 2014.

SCHMIDT, Paulo. História do pensamento contábil. Porto Alegre: Bookman, 2000.

TOBIAS, Afonso Cesar. Estudo de Caso: BalancedScorercard em uma empresa de varejo. Disponível em: <http://www.cavalcanteassociados.com.br/utd/UpToDate239.pdf>. Acesso em: 20 fev. 2015. 